DOI 10.37882/2223-2982.2021.09.37

\title{
ЛИНГВОКУЛЬТУРОЛОГИЧЕСКИЙ АНАЛИЗ ФРАЗЕОЛОГИЗМОВ С КВАНТИТАТИВНЫМ КОМПОНЕНТОМ В РУССКОМ И КИТАЙСКОМ ЯЗЫКАХ
}

\section{LINGUISTIC AND CULTURAL ANALYSIS \\ OF PHRASEOLOGICAL UNITS WITH A QUANTITATIVE COMPONENT IN THE RUSSIAN AND CHINESE LANGUAGES}

Zhang Jie

Summary: The article analyzes the linguocultural aspect of the study of Russian and Chinese phraseological units containing a quantitative component. Comparative phraseology is a relatively "young" discipline. The experience of studying such various proverbial funds as Russian and Chinese seems to be relevant. This article examines from the point of view of meaningful meaning, interprets the general Russian-Chinese cultural comparison of numbers, and then analyzes the reasons for the appearance of differences. As prospects for further research, it should be noted that there are ample opportunities provided by the comparative study of proverbs in general and with numerals in particular, for a better understanding of the mentality of peoples, a deeper understanding of the similarities and differences in cultures, traditions, symbolic representations. Therefore, their study will continue to be of great scientific interest.

Keywords: linguistic and cultural, phraseological units, quantitative, Russian, Chinese, Different;Similar.
B последнее десятилетие в российской лингвистической науке сформировалось целое направление во фразеологии - изучение фразеологических единиц с числовым, или квантитативным, компонентом на материале или одного, или, что чаще, разных языков. Исследователей интересует символика и значение чисел в составе фразеологических единиц. Когда они употребляются самостоятельно, числовые лексемы обычно реализуют прямые значения - точное выражения количества, порядок при счете и т.д. Если эти лексемы находятся в составе фразеологических единиц, их значение меняется. Обнаруживается ряд новых значений, которые можно связать с символическими значениями чисел. Символика каждого числа подробно отражена в различных литературных источниках.

Фразеологизмы как продукт устного народного творчества давно существуют в русском языке. В отечественной науке первым стал изучать русские фразеологизмы М.В. Ломоносов. В.В. Виноградов классифицировал фразеологизмы, выделив три типа на основе семантическо-

\author{
Чжан Цзе \\ Старший преподаватель, Шихэцзыский университет КНР \\ (2. Шихэизы) \\ 34634857@q9.com
}

Аннотация: В статье анализируется лингвокультурологический аспект исследования русских и китайских фразеологизмов, содержащих квантитативный компонент. Сопоставительная фразеология является относительно "молодой" дисциплиной. Актуальной представляется опыт изучения таких различных пословичных фондов как русский и китайский. Данная статья исследует с точки зрения толкового значения, интерпретирует общее русско-китайское культурное сопоставление цифр, потом анализирует причины появления отличий. В качестве перспектив дальнейшего исследования нельзя не отметить, широкие возможности, которые дает сопоставительное изучение пословиц в целом и с именами числительными в частности, для лучшего понимания менталитета народов, более глубокого осознания сходств и отличий в культурах, традициях, символических представлениях. Поэтому их изучение и в дальнейшем будет представлять большой научный интерес.

Ключевые слова: лингвокультурологический, фразеологизмы, квантитативный, русский язык, китайский язык, различие, сходство.

го признака (степени семантической слитности): фразеологические сращения, фразеологические единства и фразеологические сочетания. Н.М. Шанский предложил внести в классификацию выражения (поговорки, пословицы и крылатые выражения). Данная статья основывается на точке зрения Н.М. Шанского на природу фразеологизмов. «Фразеологизм - это воспроизводимая в готовом виде языковая единица, состоящая из двух или более ударных компонентов словного характера, фиксированная (т. е. постоянная) по своему значению, составу и структуре» $[7$, с. 22].

Имеющая многовековую историческую традицию китайская языковая культура по праву считается неисчерпаемым источником различного рода красочных по форме, заключающих в себе глубокий внутренний смысл, устойчивых языковых конструкций-идиом, включающих народные поговорки, высказывания исторических персон, цитаты из древних книг и др. Разные учёные представляют разногласия по определению китайских фразеологизмов. В книге «Современный китайский язык» 
(2002) Хуан Божун, Ляо Сюйдун (黄伯荣,廖序东) описаны китайские фразеологимзы Чэньюй (четырехкомпонентные сочетания иероглифов называются «Чэньюй», они построены по нормам древнего китайского языка), недоговорки-иносказания (Предложение, состоящее из двух частей, которые строятся по принципу «загадка» (иносказание) - разгадка (раскрытие иносказания)) и привычные выражения (устойчивые словосочетания) [5]; в книге «Общий обзор китайских фразеологизмов» (2003) у Чжанькунь(武占坤) думает, что китайские фразеологизмы содержают в себе чэньюй, пословица, поговорка, привычные выражения, недоговорки-иносказания[4]. Другие учёные Ли Ханьвэнь, Шао Цзинминь, Чжан Пинь (李翰文, 邵敬敏，张斌) определяют фразеологизмы следующим образом:

\begin{tabular}{|c|c|c|c|c|c|}
\hline & 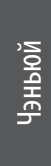 & 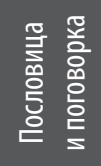 & 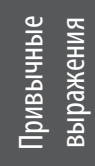 & 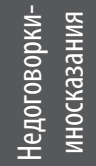 & 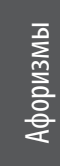 \\
\hline $\begin{array}{c}\text { Ли } \\
\text { ХаньВэнь }\end{array}$ & $\sqrt{ }$ & $\sqrt{ }$ & $\sqrt{ }$ & $\sqrt{ }$ & $\sqrt{ }$ \\
\hline $\begin{array}{c}\text { Шао } \\
\text { Цзинминь }\end{array}$ & $\sqrt{ }$ & $\sqrt{ }$ & $\sqrt{ }$ & $\sqrt{ }$ & \\
\hline $\begin{array}{l}\text { Чжан } \\
\text { Пинь }\end{array}$ & $\sqrt{ }$ & & $\sqrt{ }$ & $\sqrt{ }$ & \\
\hline
\end{tabular}

Именно поэтому изучение сосредоточено не на все квантитативные фразеологизмы, только на пословицы и поговороки, которые представляют собой особый класс единиц во фразеологии.

Фактический материал составил 516 пословиц, в которых используются числительные. Из них 386 примеров русских пословиц и 130 китайских.

Активность числительных подсчитывалась в соответствии со встречаемостью каждого числительного во всем пословичном корпусе данного языка.

Активность числительных и их принадлежность к разряду количественных в русских и китайских пословицах представлены в Таблице 1.

Первое место в пословицах всех языков принадле- жит количественному числительному один. Первые три места в русских пословицах занимают один, два, mpu; для китайских пословиц это один, тысяча, сто. Следует заметить, что в русских и китайских пословицах с квантитативным компонентом часто встречается цифра один, два, mpи, четыре и сто. Именно это и является главным объектом исследования в данной статье.

О философском значении один хорошо сказано в работе Тан Аошуан: [3, с. 82]. «...это и начало Вселенной и основа «десяти тысяч вещей», и единство человека с Небом». Это верно, скорее, для китайского мышления. Но вот другое высказывание Тан Аошуан кажется верным и по отношению к русскому и английскому языкам: «Это числительное парадоксальным образом сочетает в себе и идею мизерности и идею всеобъемлимости». Примеры из русских пословиц: «Один воин и тысячи водит, а бог и тысячи, и воина водит» - идея всеобъемлимости, которая подчеркивается противопоставлением с существительным «тысячи», т.е. «тьма», очень много. Но «Один в поле не воин» - идея мизерности.

В китайских пословицах и поговорках числительное один встречается в некоторых из перечисленных значений. Например:

- Противопоставление малого многому: «в одном лесу два тигра не живут (一 (山) 林难容二虎)»;“ лучше один свидетель, чем тысяча слухов (百闻不 如一见)»; «лучше сломать десять храмов, чем расстроить одну свадьбу (宁拆十座庙不毁一桩婚)»; «один человек роет колодец, тысяча людей пьют воду (一人挖井，千人喝水)»; «убей одного, чтобы напугать сотню (杀一儆百)».

- Чередование противоположностей (то Р, то не-Р): «дома и тысячу дней прожить легко, выйдешь из дому - и час трудно(在家干日好，出门一时就困 难)»; «один любит редьку, другой - дыни(夢卜甜瓜 各有所爱)》。

- Немного: «один воин - слабый воин (寡不敌众)».

На наш взгляд, некоторые контекстуально производные значения китайского иероглифа один (一) можно найти и в пословицах русского языка. Например, «Один солдат - не полк» - «немного» и «противопоставление малого многому».

Таблица 1.

Фразеологическая активность количественных числительных.

\begin{tabular}{|c|c|c|c|c|c|c|c|c|}
\hline & 10е место & 2ое место & 3-е место & 4ое место & 5ое место & бое место & 7ое есто & 8ое место \\
\hline $\begin{array}{l}\text { русские } \\
\text { пословицы }\end{array}$ & $\begin{array}{l}\text { один } \\
29 \%\end{array}$ & $\partial в a$ & mpu & семь & $\begin{array}{l}\text { cmo } \\
8 \%\end{array}$ & $\begin{array}{c}\text { четыре } \\
4 \%\end{array}$ & $\begin{array}{c}\text { десять } \\
\text { пять } \\
2,5 \%\end{array}$ & сорок \\
\hline $\begin{array}{l}\text { китайские } \\
\text { пословицы }\end{array}$ & $19 \%$ & $\begin{array}{c}\text { тысяча } \\
17 \%\end{array}$ & $18 \%$ & mpu & $\partial в a$ & десять & $\begin{array}{c}\text { десять } \\
\text { тысяч } \\
3 \%\end{array}$ & $\begin{array}{c}\text { семь/ } \\
\text { четыре } \\
1,5 \%\end{array}$ \\
\hline
\end{tabular}


Русские и китайские пословицы с числительным два. В русских пословицах это числительное занимает второе место по частотности, а китайских пословиц совсем немного. Но мы рассматриваем и совместно, т.к. некоторые их значения совпадают.

- Буквальное количественное значение: Русские пословицы: «До двух раз прощают и в третьи бьют»; «В поле две воли: кому бог поможет». Китайские пословицы: «Два человека вместе трудятся - кто из них светел, а кто темен?»

- Неопределенно-количественное значение «мало - несколько».

Русские пословицы: «Аршин на кафтан, да два на зарплаты» - «мало»; «Из двух зол выбирай меньше» - из нескольких.

Китайских пословиц с этим значением числительного не выявлено.

- Неопределенно-количественное значение «несколько - много»:

Русские пословицы: «Два раза молоду не быть, а смерти не отбыть».

Китайские пословицы: «В один рот двух ложек не впихнешь (一口不能著两勺)».

Русские, китайские и английские пословицы с числительным три.

- Буквальное количественное значение:

Русские пословицы: «Три коровушки есть, отелятся - будет шесть»; «За три вещи не ручайся: за часы, за лошадь, да за жену»; «В нашей волости три болести: рекрутство, подати да земщина».

Китайские пословицы: «Бывает три случая непочитания родителей, нет потомка - самый страшный из них (不孝有三，无后为大)».

- Неопределенно-количественное значение «много»: Русские пословицы: «Его в три охвата не обнимешь»; Наговорил с три короба»; «Ленивый три раза ходит, а скупой три раза платит»;

Китайские пословицы: «Можешь получить успехи после трех учителей (井淘三遍吃甜水, 人从三师 武艺高)».

В китайских пословицах можно выделить значение «слишком много», например: «Если хорошую речь повторить три раза - даже у собак появится отвращение (好话不说三遍)»; и значение «много - достаточно»: «У хитрого зайца три пещеры - у нищего тоже три друга(狡兔还有三窟-叫花子也有三个穷朋友)»。

- Неопределенно количественное значение «мало»: Русские пословицы и поговорки: «Заблудился в трех соснах».

Китайские пословицы: «Можешь узнать человека, когда ему было три года (从小看大，三岁看老)».

Анализ показывает, что данное числительное в не- определенно-количественном значении «много» встречаются чаще, чем в значении «мало» в пословицах всех двух языков.

Как видим, утрата точного значения числительных два, три приводит к вариантности пословиц.

В русских пословицах мы выявили неопределенно количественное значение «долго» и «коротко» часто в их противопоставлении:

Русские пословицы: «Упросились злыдни на три дня, да черт их выкурит в три года»; «Старуха три года на мир сердилась, а мир того не знал»; «Где я лисой пройду, там три года куры не несутся»; «Не страшны злыдни в 3 дня, страшны в 3 года»; «Обещанного три года ждут». Примеры показывают, что три с существительным год имеет значение «долго», а с существительным день - может иметь значение и «коротко» и «долго». Там, где есть противопоставление «день - год» в одной пословице, три имеет разные значения. Например, «Не угадывай в три дня, угадывай в три года» - три имеет значение «коротко, быстро» в первой части пословицы и значение «долго» во второй. «Говорит три дня, а все про злыдни»; «Хоть три дня не есть, а с печи не слезть» - значение «долго». В пословице «Три дня молол, а в полтора съел» три дня противопоставлено полтора дня, и три имеет значение «долго».

Русские, китайские и английские пословицы с числительным четыре.

Хотя таких пословиц немного, значения числительного и самих пословиц весьма интересны.

- Буквальное количественное значение: Китайских пословиц с таким значением нет. Русские пословицы: «Конь о четырех ногах, да спотыкается»; «Покупала по четыре денежки, а продавала пару по два грошика»; «Без троицы дом не строится, без четырех углов изба не становится»; «Четыре угла дому на строение, четыре времени году на совершение»; «У него гостят четыре угла» (никого).

- Неопределенно-количественное значение «много»: Китайская пословица:«Сегодня получится три, а завтра получится четыре (朝三暮四) ».

Русские пословицы: «Четыре полы, восемь карманов (у приказного)».

- Неопределенно количественное значение «мало»: Русская пословица: «Одна труба, четыре избы, восемь улиц (разоренное имение)».

- -Символическое значение четыре в словосочетании четыре моря:

Китайская пословица: «Среди четырех морей все люди братья (四海皆兄弟)».

Русская пословица: Четыре страны света на четырех морях положены. 
Символическое значение в употреблении числительного четыре в китайской и русской пословицах очень интересно. Это, возможно, свидетельство влияния китайской символики. Четыре легендарных моря окружало Срединное царство. Использование четыре со сторонами света - общее представление об устройстве жизненного пространства. В русских пословицах оно выражается и в словосочетании четыре угла как пространственное организация жилища [Осипова, 82]. Это сочетание используется и метонимически, т.е. оно привычно для русского народа.

Китайские пословицы с числительным сто. Числительное имеет следующие значения.

- Неопределенно-количественное значение «много-несколько»:

«Нужно читать хорошую книгу сто раз (好书不厌百 回读)»; «Убей одного, чтобы напугать сотню (杀一 儆百)»; «Сто типов болезни может вылечить, кроме одного - любовь (百病可治，相思难医)»。

- Неопределенно-количественное значение «мало - несколько»:

«Сто рублей могут купить хорошую лошадь, тысяча рублей могут купить красоту, десять тысяч рублей могут купить чиновника, а где можно купить молодость? (百金买骏马，千金买美人，万金买爵 禄，何处买青春)»; «Сто лет прошло очень быстро, а если не улыбаешься очень жалко (百岁光阴如 过客，不开口笑是痴呆)»; «Нужно нести тяжёлые вещи, иди на сто шагов (百步无轻担)»; «Здание по сто метров создал с самого начала (百尺高楼从地 起 (万丈高楼从地起) )»; 《50 шагов смеётся над 100 шагов (五十步笑一百步)».

- Значение противопоставления. Оно может сочетаться со значением «много» или « мало»: «У человека не бывает тысячи дней хороших, цветы не бывают сто дней красны (人无干日好，花无白日红)».

Русские пословицы с числительным сто представлены гораздо меньшим количеством, однако значения числительного те же, за исключением того, что нет значения «несколько».

- Неопределенно-количественное значение «много»: «Жить сто годов, нажить сто коров, меринов стаю, овец хлев, свиней». «Сто рублей давали, да из кармана не вынимали».

Часто именно числительное сто употребляется в пословице для того, чтобы выразить значение «много» (его можно выразить многими другими числительными) из-за рифмы и ритма. Например: «Где просто, там ангелов со сто; где хитро, там ни одного».

Встречается значение максимального предела: «Хоть сто лет думай, лучше этого не выдумаешь».
- Неопределенно-количественное значение «мало»: «Думай, не думай, а 100 рублей деньги»; «На сто пусто, на пятьсот ничего».

- Значение противопоставления: «Сто голов - сто умов»;«Не купи на сто, купи на стать».

Из вышеуказанных мы заметили, что среди русских и китайских пословиц и поговорок с числительными существуют сходные по смыслу, например, в русских пословицах «лучше один раз своими глазами увидеть, чем сто раз услышать»; в китайских пословицах «лучше один свидетель, чем тысяча слухов (百闻不如一见)».Это не только потому, что пословицы и поговорки могут заимствоваться, а потому, что они выражают народную мудрость, жизненные правила и установки. А жизненные устои и принципы разных народов, ответы на вопросы, что такое хорошо, а что есть плохо, во многом сходны.

Русские и китайцы любят число три, они считают, что три - счастливое число. Слушая несчастливые слова, русские должны повернуть голову к левому плечу и плюнуть три раза, чтобы избежать беды. Поэтому в русских пословицах три часто связывается с христианством: Бог любит Троицу; помни три дела: молись, терпи, работай; до трёх раз прощают и т.д. В древней книге «Дао-дэ цзин» : Дао порождает одного, один порождает двух, двое порождают трех, три порождают все сущее!(道生一、一生 二、二生三、三生万物). Так же в китайских пословицах mри часто связывается с буддизмом: везение во всех трех жизненных циклах(三生有幸). По объяснению буддизма три жизненных цикла - предыдущая жизнь, настоящая жизнь и будущая жизнь.

Число четыре напоминает кубик и квадрат в русской культуре, и символизирует землю и пространство. В русских пословицах четыре часто связывается с временами года и четырьмя сторонами света: на все четыре стороны; четыре угла дому на строение, четыре времени году на совершение. В древнем Китае люди считали, что "небо кругло, а земля квадратна", а квадрат состоит из четырёх линий, поэтому в китайских пословицах четыре так же связывается с временами года и четырьмя сторонами света: со всех сторон слышатся песни Чусцев (быть окружённым врагами со всех сторон 四面楚歌); четыре времени года и восемь праздников солнечного календаря ( 四时八节).

Существует большое различие в отношении к числу два между русскими и китайскими культурами. Русские считают, что четное число - неудачное число, а нечетное число - счастливое число, именно поэтому русские дарят букет цветов близким с нечетным количеством. В русских пословицах два ассоциируется с чертом: чёрта с два. Наоборот, китайцы очень любят четное число, они считают, что число два - символ любви и верности: двойное счастье у дверей(双喜临门), обе(две) стороны извле- 
кают для себя выгоду (两全其美).

Таким образом, культурные коннотации, придаваемые числам в Китае и России, различны и похожи.
Изучение коннотации цифровой культуры может помочь нам лучше понять языковые знания и выявить общие черты и различия между русской и китайской культурой.

\section{ЛИТЕРАТУРА}

1. 李翰文. 熟语集锦. 北京: 北方联合出版传媒股份有限公司，2009.(Ли Ханьвэнь. Сборник фразеологизмов. - Пекин: Издательство Бэй Фан Лян Хэ, 2009)

2. Осипова А.А. Семантическая и символическая структура лексем со значением числа «пять». // Актуальные проблемы лингвистической культурологи3. Сб.статей. М.: Прометей, 2005. с.81-87.

3. Тань Аошуан. Китайская картина мира. М., Языки славянской культуры, 2004.

4. 武占坤. 汉语熟语通论. 保定: 河北大学出版社，2007. (У Чжанькунь. Общий обзор китайских фразеологизмов. - Баодин: Издательство Хэбэйского университета, 2007)

5. 黄伯荣，廖序东. 现代汉语. 北京：高等教育出版社，2002. (Хуан Божун, Ляо Сюйдун. Современный китайский язык. - Пекин: Издательство вышего образования, 2002)

6. 张斌. 新编现代汉语. 上海: 复旦大学出版社， 2005. (Чжан Пинь. Современный китайский язык. - Шанхай: Издательство Фуданского университета, 2005.)

7. Шанский Н.М. Фразеология современного русского языка: Учеб. Пособие для вузов по спец. “Русский язык и литература”.—--е., изд., испр. и доп. СПб::Специальная Литература, 1996

8. 邵敬敏. 现代汉语通论. 上海：上海教育出版社， 2002.(Шао Цзинминь. Соременный китайский язык. - Шанхай: Издательство Шанхайского образования, 2002).

( ) Чжан Цзе (34634857@qq.com).

Журнал «Современная наука: актуальные проблемы теории и практики»

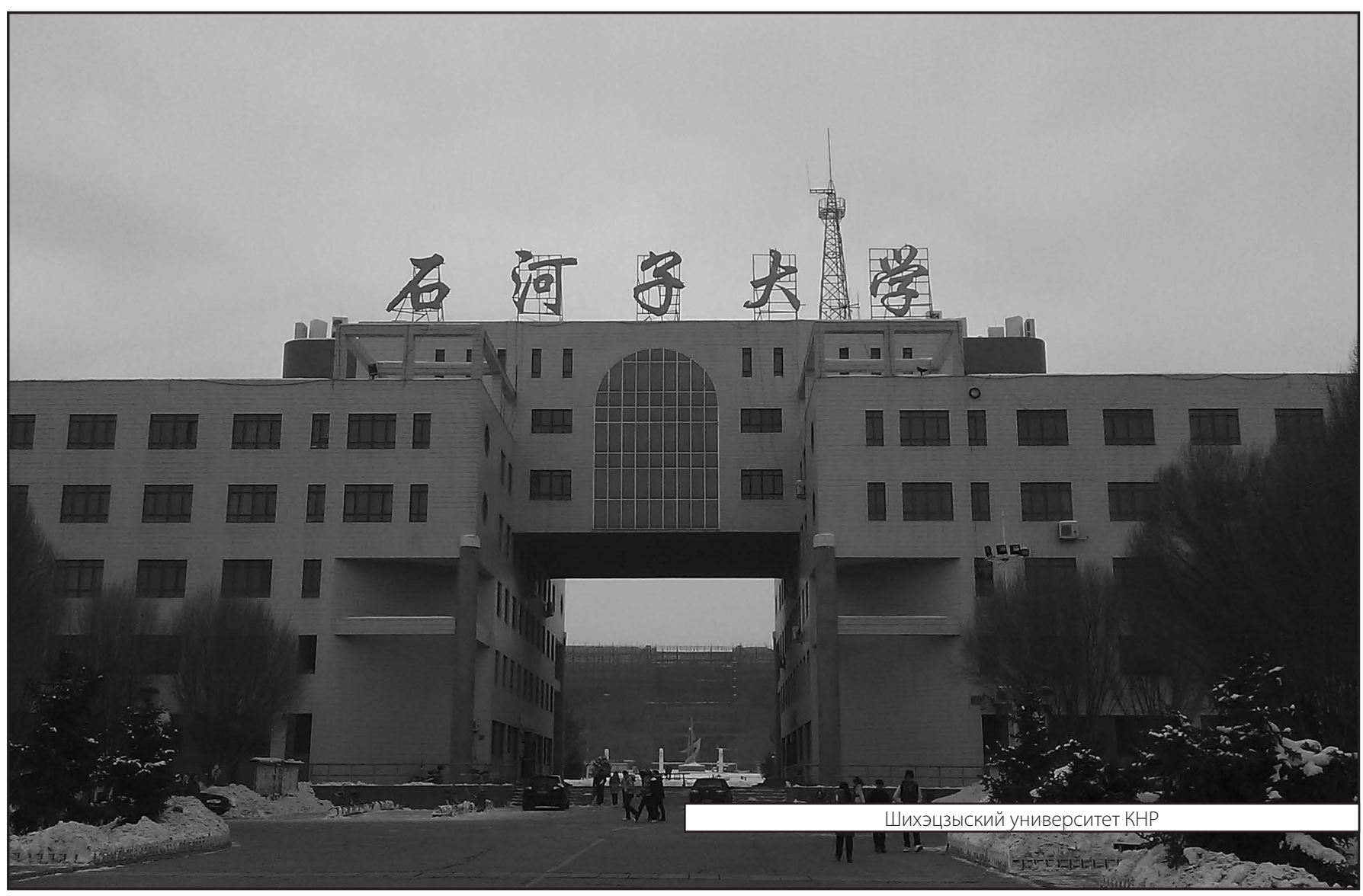

